\title{
A Comparative Study for the Role of Preoperative Antibiotic Prophylaxis in Prevention of Surgical Site Infections
}

\author{
${ }^{1}$ Prashant Dhanke, ${ }^{2}$ Prakash Gurav, ${ }^{3}$ Subodh Ugane \\ ${ }^{1}$ Asst. Prof, MS Gen Surg, GMC Miraj. \\ ${ }^{2}$ Prof and HOD, MS Gen Surg, GMC Miraj. \\ ${ }^{3}$ Assoc. Prof, MS Gen Surg, GMC Miraj.
}

\section{Introduction}

Surgical site infection (SSI) is one of the most frequent causes of postoperative morbidity. Surgical site infection is the most common nosocomial infection in our population accounting for 38\% of all infections in surgical patients. Incisional infections are the most common accounting for $60 \%$ to $80 \%$ of all SSIs ${ }^{1}$.

The emergence of prophylactic antibiotics has made a huge contribution towards extending range and complexity of surgical procedures.

The antibiotic era which began more than 5 decades ago has revolutionized the treatment of surgical infection particularly during post operative period. It has led to reduction in surgical site infections which complicate the clinical management of surgical patients often lengthening hospital stay and increasing cost of providing medical care.

The explanations for this continuing problem with infection is obviously multifactorial but the wide spread use of antibiotics has frequently resulted in an unrealistic over dependence on their effectiveness in treating disease with consequent violation of established surgical principles and the breakdown of isolation procedures.

The concept of preoperative antibiotic prophylaxis was mooted by Stranchan in 1977, where he compared a single preoperative dose of Cefazoline with regime of Cefazoline given for a period of 5 days post operatively. The infection rate seen in single dose was $3 \%$ and in multiple post operative dose was $5 \%{ }^{2}$.

Prophylactic antibiotic therapy is clearly more effective when begun preoperatively and continued through the intra operative period with the aim of achieving therapeutic blood levels throughout the operative period $^{3}$.

In the current study we want to emphasize on the role of antibiotic prophylaxis administration to clean and clean-contaminated surgical cases in this institution.

\section{Objectives}

$\square$ To identify the need of using antibiotic prophylaxis in clean, clean-contaminated surgical wounds.

$\square$ To study whether prophylactic antibiotic is itself sufficient to minimize

surgical site infection.

\section{Methodology}

This is a prospective open label study. The material of this study consists of cases admitted to our Tertiary care hospital and Teaching Institute from January 2011 to December 2012 for a period of 2 years. During this period, 100 cases were selected for our study purpose, all of which were clean or clean contaminated surgeries done under meticulous surgical technique.

\section{Methods:}

This study involves only clean or clean contaminated cases of elective surgeries. The study group involves 100 clean or clean contaminated surgeries done in our hospital. The group was split into group A and group B of 50 cases each. Group A comprises patients who received a pre-operative single dose of ceftriaxone a broad spectrum cephalosporin. Group B received no such prophylactic antibiotic. The groups were split into two taking into consideration the type of surgeries, the age of the patient, the presence or absence of risk factors for development of SSI, and associated medical conditions, all of which were represented in both the groups almost equal and a comparative clinical study was made.

On admission to the hospital, a detailed proforma was completed which includes the diagnosis preoperative investigations and meticulous pre-operative patient preparation. All the patients were followed upto ten days post operatively. Data was entered in the proforma. Wound swabs were sent for culture and sensitivity and the patients were treated accordingly. Patients were admitted on our out-patient days. Patients were 
categorized as clean or clean contaminated cases depending on their complaints, clinical examination and diagnosis. Patients with remote infections like respiratory tract infections or urinary tract infections were treated on out-patient basis and taken up for surgery after 2 weeks. All patients were admitted 2 days prior to surgery after getting thoroughly investigated and also some special investigations in selected cases to clinch the diagnosis was performed. Preoperative hospital stay was minimized to prevent the patient from getting the access to hospital infections. Patients with diabetes mellitus were treated appropriately with injectable insulin under precaution.

Preoperative skin preparation was done meticulously. Patients allowed to take a through scrub bath after which parts were prepared with povidone iodine and was isolated from the surrounding by covering operative site by sterile gauze ${ }^{4}$. Patients were brought to the waiting room next day morning and were given single dose of iv ceftriaxone $1 \mathrm{gm}$ under aseptic precaution half an hour before the surgery. All the cases were done in the morning hours. Patients were anesthetized under aseptic precaution. Sterile gauze was removed and patient's skin was painted with povidone iodine solution and sprit. Then the surface was allowed to dry. Then it was covered with sterile towels and sheets. Surgery was performed by senior staff and postgraduates, whenever possible, cautery was minimized. Movement in the operating room was restricted. Whenever necessary closed suction drain was preferred and wound was closed with sterile dressings.

Patients were isolated in the postoperative ward for at least 3 days. Drains were removed on $3 \mathrm{rd}$ or 4 th postoperative day. Wound was inspected on third day, any sign of inflammation, infection were noted down and findings were entered in the proforma. If infected, wound swab was taken and sent for culture and sensitivity and antibiotic was started immediately in all infected cases. Sutures were removed on the eighth postoperative day. Patients were followed up to fifteenth postoperative day. All the data was entered in the proforma. The available results and outcomes in both groups were studied and analyzed and then they were compared with the available previous study and final conclusion was drawn.

Patients giving written and informed consent were included in the study. All tenets of declaration of Helesinki were followed during the study.

\section{Results}

The study involved 100 clean and clean contaminated elective surgical cases admitted to our Tertiary care hospital and Teaching Institute from January 2011 to December 2012 for a period of 2 years. Where they were divided equally into two groups, Group A included 50 cases who received single prophylactic dose of 1 gm cefotriaxone given intravenously half an hour before surgery and Group B included 50 cases who did not receive any such antibiotic prior to surgery.

The age incidence varied from 5 to 65 years but maximum number of patients belonged to 21 to 30 years age group. Six patients in group B were infected, one belonged to 41-50 years age group three belonged to the 51-60 years age group and other two in the 61-70 years age group.

\section{Infection Rate}

Group A had 35 clean surgical cases and 15 clean contaminated cases, out of which none of them were infected. In group B out of 35 clean cases, 1 case was infected and out of 15 clean contaminated cases 5 were infected.

TABLE NO. 1- Infection Rates in all cases.

\begin{tabular}{|l|l|l|l|l|l|l|}
\hline & \multicolumn{2}{|l|}{ Number of cases } & Number of cases which got infected & Rate of infection \\
\cline { 2 - 7 } & Clean & $\begin{array}{l}\text { Clean- } \\
\text { C0ntaminated }\end{array}$ & Clean & $\begin{array}{l}\text { Clean- } \\
\text { C0ntaminated }\end{array}$ & Clean & $\begin{array}{l}\text { Clean- } \\
\text { COntaminated }\end{array}$ \\
\hline Group A & 35 & 15 & - & - & - & - \\
\hline Group B & 35 & 15 & 1 & 5 & $2.86 \%$ & $33.33 \%$ \\
\hline Total & 70 & 30 & 1 & 5 & $1.43 \%$ & $16.66 \%$ \\
\hline
\end{tabular}

Risk Factors :

Out of 100 cases taken up for the study 37 patients were identified to have risk factors for development of surgical site infection. The incidence and distribution of risk factors is as follows.

TABLE NO.2- Showing distribution of risk factors in the affected group

\begin{tabular}{|l|l|l|l|l|}
\hline Risk Factors & Group A & Group B & Total & Percentage (\%) \\
\hline Anaemia & 4 & 4 & 8 & 20.51 \\
\hline Diabetes Mellitus & 3 & 3 & 6 & 15.38 \\
\hline Obesity & 4 & 6 & 10 & 25.64 \\
\hline $\begin{array}{l}\text { Prolonged duration } \\
\text { of surgery }\end{array}$ & 0 & 7 & 7 & 15.38 \\
\hline Old age & 4 & 4 & 8 & 20.51 \\
\hline
\end{tabular}




\begin{tabular}{|l|l|l|l|l|}
\hline Total & 15 & 24 & 39 & 100 \\
\hline
\end{tabular}

In the present study 6 patients in group B with obesity were found to have prolonged duration of surgery contributing to more than one risk factor for development of SSI. All the 6 patients who had prolonged duration of surgery and obesity developed surgical site infection. The 6 patients with diabetes mellitus (3 patients in each group) who had control of their diabetic status prior to surgery, none of them developed SSI. 8 patients with anemia (corrected prior to surgery) did not develop SSI. Out of 8 patients with old age 4 developed SSI, these 4 had other associated risk factors.

\section{Duration of Surgery}

All the cases in this study were clean and clean contaminated elective surgeries conducted by senior staff and postgraduates. Care was taken to complete the surgery as early as possible and efficiently. The average duration of the surgery in our study from the time of skin incision to the time of closure was 1 hour 30 minutes. The minimum time was 35 minutes and maximum time was two hours. Two patient in our study who got infected the duration was 1 hour and 50 minutes and the other 4 patients who got infected the duration was more than two hours. No patients who surgery was done below one and half hour got infected in both the groups.

TABLE NO.-3 Showing Duration of Surgery affecting infection rate

\begin{tabular}{|l|l|l|l|l|}
\hline \multirow{2}{*}{$\begin{array}{l}\text { Duration in } \\
\text { Hours }\end{array}$} & Number of cases & Number of cases infected & $\begin{array}{l}\text { Percentage } \\
\text { Infection }\end{array}$ \\
\cline { 2 - 5 } & Group A & Group B & & - \\
\hline$<1$ hour & 35 & 32 & - & $15.38 \%$ \\
\hline $1-2$ hours & 15 & 13 & 2 & $80 \%$ \\
\hline
\end{tabular}

\section{Drains}

In the present study 30 patients were provided with closed suction drainage and none of them got infected, contributing to the use of closed suction drainage to prevent surgical wound infection rather than the open drainage method.

\section{Antibiotic and Timing of Antibiotic Prophylaxis :}

In the present study a third generation cephalosporins was administered half an hour before the incision under aseptic precaution to all the patients in group A and no patients in group A got infected when compared to the group B, where no such antibiotic was given and there was an infection rate of $2.86 \%$ ( 1 patient) in clean cases and $33.33 \%$ (5 patients) in clean contaminated cases. There were no reports of any allergy and adverse effects to the prophylactic drug chosen.

TABLE NO.4- Showing Infection Rate with and without Prophylactic Antibiotics in clean and clean contaminated cases

\begin{tabular}{|c|c|c|c|c|}
\hline & & Number of cases & $\begin{array}{l}\text { Number of cases } \\
\text { Infected }\end{array}$ & Percentage \\
\hline \multirow[t]{2}{*}{ Clean } & Group A & 35 & - & - \\
\hline & Group B & 35 & 1 & $2.86 \%$ \\
\hline \multirow{2}{*}{$\begin{array}{l}\text { Clean } \\
\text { Contaminated }\end{array}$} & Group A & 15 & - & - \\
\hline & Group B & 15 & 5 & $33.33 \%$ \\
\hline
\end{tabular}

\section{Discussion}

Surgical site infection though has been documented ever since origin of surgery, has not been able to be mastered. Strict asepsis, meticulous surgical techniques, prophylactic antibiotic have drastically reduced the incidence of SSI

Age Incidence

Though surgical site infection affects all age group its incidence increases with age and is seen frequently in older age group. In our present study maximum number of case were represented in age group 21 30 years. The age incidence in the present study varied from 5 to 65 years but maximum number of patients belonged to 21 to 30 years age group.

Older age group is considered a risk factor for development of SSI, in the present study all the 5 infected cases were 6o years and above age group and one case in 41-50 years age group. Rao et $\mathrm{al}^{5}$ showed in their study that SSI incidence doubled in older age group 50-70 years.

\section{Role of Risk Factors}

In the present study the patient factors when controlled prior to surgery did not cause any infection. But 5 patients in group B who where obese and underwent prolonged duration of surgery had infection. 
Total 10 patients in the present study were obese (4 in group A, 6 in group B) all the 6 patients in group B got infection. These 6 cases had prolonged duration of surgery, two cases it was 1 hour and 50 minutes, rest all 4 cases it was more than 2 hours. Here 5 cases belonged to old age group .It can be said from the present study that presence of more than one risk factor has a significant impact on the development of surgical site infection and when not provided with adequate antibiotic coverage (prophylactic antibiotic dose) are at definite risk of development of surgical site infection.

Cruise and Ford have demonstrated that presence of obesity as a single independent risk factor for development of SSI and the prolonged time of surgery also increases the incidence of surgical site infection ${ }^{6}$.

Anaemia was present in 8 patients all the 8 patients were treated preoperatively for correction of anaemia. Their hemoglobin levels were corrected prior to surgery and then taken up for surgery. The patients were equally distributed in both the groups, 4 in group A and 4 in group B. None of them developed surgical site infection. Hence anemia when corrected preoperatively does not pose a risk for development of surgical site infection.

In the present study, 6 patients were diabetic (group A-3, Group B-3) their blood sugar level was well controlled before and after surgery. Funary AP et al. in their study showed that when blood glucose level were kept strictly below $200 \mathrm{mg} / \mathrm{dl}$ during the perioperative period by continuous intravenous infusion of insulin reduced the incidence of SSI from $24 \%$ to $6.06 \%$ which was statistically significant ${ }^{7}$. None of the patients got infected so it can be said that with the proper control of diabetic status, infection rate can be reduced.

\section{Types of Surgery Undertaken}

The type of surgery undertaken had significant role in development of SSI. The different studies in accordance with our study are as follows:

TABLE NO.5: Types of Surgeries and Infection Rate

\begin{tabular}{|l|l|l|l|}
\hline Studies & Clean & Clean-Contaminated & Contaminated \\
\hline Lilani et al $^{8}$ & $3.68 \%$ & $22.4 \%$ & $32.45 \%$ \\
\hline Cruse et al $^{6}$ & $7 \%$ & $18 \%$ & $>35 \%$ \\
\hline Present Study & $1.43 \%$ & $16.66 \%$ & - \\
\hline
\end{tabular}

Out of total 100 cases 70 were clean and 30 clean-contaminated surgical cases. All types of cases were equally represented in both the groups.

\section{Duration of Surgery}

Various studies indicate that there is a direct relationship between the length of the operating time and the rate of infection of clean wounds roughly double with every hour of operating time and is as shows in the various studies done previously in the table below.

Table 6: Comparison of Wound Infection Rate in Relation to the Duration of Operation

\begin{tabular}{|l|l|l|l|}
\hline \multirow{2}{*}{ Study } & \multicolumn{3}{|c|}{ Time in Hours } \\
\cline { 2 - 4 } & $0-1$ Hours & $1-2$ Hours & $>2$ Hours \\
\hline Cruise and Ford $^{6}$ & $1.4 \%$ & $1.8 \%$ & $4.4 \%$ \\
\hline Lilani et al & - & $1.47 \%$ & $38.46 \%$ \\
\hline Present Study & - & $15.38 \%$ & $80 \%$ \\
\hline
\end{tabular}

Thus our study proves that there is a direct relationship between the length of the operating time and infection rate, the rate of infection of clean wounds roughly double with every hour of operating time. The explanation of high infection rate in $>2 \mathrm{hrs}$ group in the present study is probably because of the small number of cases in that group.

\section{Antibiotic and Timing of Antibiotic Prophylaxis}

In the present study the use of third generation cephalosporins is justified as it is used as a single dose and is having a prolonged half life up to 8 to 12 hours which will take care of the wound in its initial crucial phase. It was administered half an hour before the incision under aseptic precaution to all the patients in group A and no patients in group A got infected when compared to the group B, where no such antibiotic was given and there was an incidence of infection rate of $8.33 \%$ (1 patient from clean surgeries and 5 from clean-contaminated surgeries were infected). 
TABLE NO. 7: The Present Study is Compared with that of the Similar Studies Conducted in the Past for clean cases

\begin{tabular}{|l|l|l|l|l|l|}
\hline Study & $\begin{array}{l}\text { No Antibiotic } \\
\text { administered, } \\
\text { Number of patients }\end{array}$ & $\begin{array}{l}\text { Percentage of } \\
\text { Infections }\end{array}$ & $\begin{array}{l}\text { Prophylactic } \\
\text { Antibiotic } \\
\text { Administered, } \\
\text { Number of patients }\end{array}$ & $\begin{array}{l}\text { Percentage } \\
\text { Infections }\end{array}$ & of value \\
\hline${\text { Carlson et } \mathrm{al}^{9}}^{9}$ & 58 & $24.1 \%$ & 60 & $3.3 \%$ & Not Significant \\
\hline Rao et $\mathrm{al}^{5}$ & 100 & $2.3 \%$ & 100 & $1 \%$ & Not Significant \\
\hline Present study & 35 & $2.86 \%$ & 35 & 0 & $\mathrm{P}=0.3207$ \\
\hline & 15 & $33.33 \%$ & 15 & 0 & $\mathrm{P}=0.0365$ \\
\hline
\end{tabular}

In the present study the overall incidence of infection in the study group B was $4 \%$ compared to be nil in study group A. In the present study for clean cases, incidence of infection in group B was $2.86 \%$ compared to nil in group A, that means the difference in occurrence of infection between two study groups was found to be non significant $(\mathrm{P}=0.3207)$. Whereas for clean-contaminated cases incidence of infection in group $\mathrm{B}$ was $26.66 \%$, that means the difference in occurrence of infection in two study groups was found to be significant $(\mathrm{P}=0.0365)$.

\section{Conclusion}

From this study we can conclude that, for clear cut cases of clean surgeries there is no need for prophylactic antibiotics, as there is no statistical significance, whereas in clean contaminated cases antibiotic prophylaxis is recommended as it is statistically significant.

\section{Bibliography}

[1]. Lewis RT, Klein H. Risk factors and post operative sepsis : Significance of preoperative lymphocytopenia. J Surg Res 1975; 26 : 365-371.

[2]. Strachan CJ, Black JP. Prophylactic use of Cefazolin against sepsis after cholecystectomy British Journal of Medicine 1977; 1: 1254-7.

[3]. Page CP, Bohnen JM, Fletcher JR et al. Antimierobial prophylaxis for surgical wounds: Guidelines for clinical care. Arch Surg $1993 ; 128: 79-88$.

[4]. Rao AS, Harsha M. Post operative wound infection. J India Med Assoc $1975 ; 44$ :90-3.

[5]. Hamilton HW, Hamilton KR, Lone FJ. preoperative hair removal. The Canadian Journal of Surgery $1997 ; 20$ :269-275.

[6]. Cruise PJE and Foord R. A five year prospective study of 23,649 surgical wounds' Archives of surgery $1913 ; 107: 206$.

[7]. Funary AP, Zerc KJ, Grunkemeier GC, Starr A. Continuous intravenous insulin infusion reduces the incidence of deep sternal wound infection in diabetic patients after cardiac surgical procedures. Ann Thorac Surg 1999; 67 :352-360.

[8]. Lilani, Jangale N. Department of microbiology, Department of surgery, Grant medical college, Byculla, Mumbai Indian J Surg 1997 ;90-3.

[9]. Carlson GE, Gonnlanakis C, Tsatsakis A. Pre-incisional single dose ceftriaxone for prophylaxis of surgical wound infection, American Journal of Surgery $1995 ; 170$ (4) : 353-5. 